\title{
The Use of Accounting in Supporting Sustainable Tourism: The Case of the Sri Lankan Hotels
}

\section{Gunarathne N.}

\author{
Department of Accounting, Faculty of Managemnet studiesand Commerce, \\ University of Sri Jayewardenepura, Nugegoda, Sri Lanka \\ *adnuwan@gmail.com
}

\begin{abstract}
Around the world sun-and-sand tourism has become matured as a market compelling the tourism industry to focus on experiential tourism which encompasses sustainable tourism as well. With the recovery of the global economic slowdown and end of North East conflict, the tourism sector in Sri Lanka is poised to mark a steady growth. The Sri Lankan hotels have taken various sustainability strategies to attract tourists who are getting increasingly concerned of the impact of their activities on the environment/society. In this context, Environmental and Sustainability Management Accounting (EMA) emerges as a potential accounting tool that can support the sustainability strategies pursued by hotels. Due to the paucity of research in this area, the study attempted to identify the drivers of EMA, the process of implementation and the challenges faced.
\end{abstract}

The study followed a qualitative multiple case study approach in order to facilitate an in depth analysis. Primary data were collected by conducting eighteen semi structured interviews covering six publicly listed hotels. This was then supported by observations of some environment-related facility centres. Sustainability reports, annual reports, internal company records such as Green Book, daily and monthly material and energy records, etc. were content analysed as secondary sources of data. While collecting data, actions were taken to improve the validity and reliability. The data gathered were analysed thematically.

The study identified that favourable public image as the main driver of EMA practices of the hotels. Internal pressures such as group affiliation, top management compulsion and the need for environmental management system accreditation also had an impact in shaping the EMA practices. When implementing these strategies the hotels seek the support of employees, guests and suppliers. It is further identified that engineers play a key role in implementing the environmental and EMA practices. Lack of proper guidance/awareness and fragmented conventional management accounting principles were identified as the main challenges faced by the hotels for better application of EMA. This has resulted in a low level development in terms of accounting. Thus, the Sri Lankan hotels can be benefited greatly if accounting can play a vital role in implementing strategies aimed at promoting sustainable tourism.

Keywords: Environmental and sustainability management accounting (EMA), Environmental/sustainability practices, Hotel industry, Sri Lanka, Sustainable tourism 